\title{
Quality of life following surgical treatment of lesions within the pineal region
}

\author{
*Stepan Fedorko, MD, Klaus Zweckberger, MD, PhD, and Andreas W. Unterberg, MD, PhD \\ Department of Neurosurgery, University of Heidelberg, Germany
}

\begin{abstract}
OBJECTIVE Pineal region tumors are a rare and heterogeneous group of lesions. The optimal therapeutic approach is currently a topic of controversy, particularly in light of the potential operative risks and complications. The potential beneficial effects of surgery have already been described, but information about neurological outcome and, in particular, health-related quality of life (HRQOL) is still lacking in the literature. The aim of this study was to assess the therapeutic effect of resection of pineal region lesions, emphasizing grade of tumor resection, neurological outcome, quality of life, and the necessity of additional shunt procedures.
\end{abstract}

METHODS The authors performed a prospective study of HRQOL in 32 patients who had undergone surgical treatment of lesions in the pineal region (20 tumors and 12 cysts) between 2008 and 2014. All patients had at least 6 months of follow-up, with reexamination including standardized neurological assessment, an evaluation of dependency using the modified Rankin Scale, and an evaluation of HRQOL. The authors retrospectively examined patient charts and collected information regarding imaging studies, neurological status prior to surgery, surgical strategies used, any complications, and histological diagnoses.

RESULTS In this study, there was no surgery-associated mortality or major morbidity. Permanent minor morbidity was reported for 4 patients (13\%). Comparing pre- and postoperative neurological symptoms, $75 \%$ of tumor patients had either complete resolution or improvement of preoperative symptoms; symptoms were unchanged in $10 \%$ of tumor patients and deteriorated in $15 \%$. In patients with pineal cysts, long-term follow-up showed that $42 \%$ of patients were free of any symptoms and $58 \%$ experienced improvement of their preoperative symptoms. These outcomes were also reflected in the modified Rankin Scale scores, which demonstrated significant improvement following resection of pineal region lesions. Furthermore, significant improvements in HRQOL scores occurred in global health status, in all functional scales, and in pain, nausea and vomiting, fatigue, and insomnia $(p<0.0001)$. Moreover, a significant reduction in the necessity for permanent shunt procedures was observed after gross-total tumor resection compared with subtotal resection $(p=$ $0.035)$ of pineal cysts.

CONCLUSIONS Despite potential risks, (radical) surgery is a highly effective and safe treatment option for pineal region lesions and should be considered for the majority of patients.

https://thejns.org/doi/abs/10.3171/2017.7.JNS17260

KEY WORDS pineal region tumors; resection; neurological outcome; quality of life; oncology

$\mathrm{L}$ ESIONS within the pineal region are rare and deeply located within the central part of the brain. They represent about $0.4 \%-1 \%$ of all intracranial neoplasms in Europe ${ }^{19}$ and about 3\%-3.2\% in Asia and Japan. ${ }^{23}$ These lesions furthermore account for $2.7 \%-11 \%$ of all pediatric brain tumors. ${ }^{39}$ Due to the histoanatomical diversity of the pineal region, neoplasms in this location are heterogeneous. They can be classified into 4 groups:
1) germ cell tumors, 2) pineal parenchymal cell tumors, 3) glial cell tumors, and 4) miscellaneous tumors and cysts. ${ }^{5}$ Common symptoms caused by lesions within the pineal region include signs of obstructive hydrocephalus $(\mathrm{OH}$; headache and nausea and vomiting) due to blockage of the cerebral aqueduct, diplopia, Parinaud syndrome, cerebellar signs, and hemisyndromes caused by a mass effect on the tectum, the cerebellum, or the brainstem. Standard clinical

ABBREVIATIONS EORTC = European Organisation for Research and Treatment of Cancer; GTR = gross-total resection; HRQOL = health-related quality of life; mRS = modified Rankin Scale; $\mathrm{OH}=$ obstructive hydrocephalus; $\mathrm{PFO}=$ patent foramen ovale; $\mathrm{QLQ}-\mathrm{C} 30$ = quality of life questionnaire-core 30; $\mathrm{QOL}=$ quality of life.

SUBMITTED January 30, 2017. ACCEPTED July 6, 2017.

INCLUDE WHEN CITING Published online March 2, 2018; DOI: 10.3171/2017.7.JNS17260.

* S.F. and K.Z. contributed equally to this work. 
evaluation includes high-resolution MRI and assessment of tumor markers in blood serum or in CSF samples.

Due to the histological diversity of these lesions and the complex anatomy of the pineal region, treatment often requires an interdisciplinary approach, including surgery, radio- and/or chemotherapy, and CSF shunting. Surgery for these tumors in the early 20th century was associated with high rates of mortality and morbidity ${ }^{11}$ as a result of the central location of the pineal region and its immediate vicinity to the deep venous system and highly eloquent brain regions. Therefore, a conservative treatment regimen consisting of CSF shunting, debulking surgery, and radiotherapy was often advocated. ${ }^{44}$ In recent decades, however, advances in microsurgical techniques, as well as in imaging and anesthesia, have resulted in improved outcomes after resection. The current mortality rate is about $1.6 \%$ (range $0 \%-8 \%$ ), the major morbidity rate about $3.0 \%$ (range $0 \%-19 \%$ ), and the minor morbidity rate about $10.8 \%$ (range 0\%-24\%). ${ }^{7-10,12,21,22,24,29,30,36,40,47,51}$ Therefore, surgery has now gained a central role in the treatment of these tumors, largely replacing conservative treatment.

Surgical mortality and neurological parameters are no longer the only measurements of outcome; in recent years, postoperative health-related quality of life (HRQOL) has gained importance as a secondary outcome parameter after brain tumor treatment. ${ }^{2,41,53,55,56}$ Despite the increasing importance of assessing HRQOL after brain surgery, there is a paucity of data available on this topic for patients with pineal region tumors. Current treatment recommendations are therefore based on single-center retrospective studies and at the discretion of the individual surgeon. Even within these studies, little is written about neurological outcome after surgery, and analysis of HRQOL is completely absent.

Data on postoperative HRQOL could have significant value in helping to choose the optimal therapy for patients with lesions within the pineal region, as well as contribute to a better understanding of neurological and neuropsychological conditions following surgery.

\section{Methods}

\section{Patient Characteristics and Study Design}

This single-center study included 32 adult patients who underwent surgical treatment of pineal region lesions performed by the senior author (A.W.U.) at our department between 2008 and 2014 and had at least 6 months of follow-up. Patients revisited our department for followup evaluation, and standardized neurological examinations and assessment of disabilities in daily activity were consecutively and prospectively performed. Patients furthermore completed a questionnaire regarding HRQOL and answered questions referring to tumor- and surgeryspecific issues. Imaging studies were performed prior to and at least once after surgery and were retrospectively assessed for this study. Furthermore, we examined patient charts and collected information regarding imaging studies, neurological status prior to surgery, surgical strategies used, any complications, and histological diagnoses.

The local standing committee on ethical practice of the medical faculty approved the protocol of this study.

\section{Clinical Examination}

\section{Neurological Assessment}

Neurological assessment, which included assessment for cranial nerve palsies, paresis, cerebellar symptoms, and sensory deficits, was performed prior to and after surgery and at least once during the follow-up examinations that occurred at least 6 months after surgery.

Neurological morbidity was defined as the occurrence of a new neurological symptom associated with the surgery. Permanent neurological morbidity or deterioration was defined as a symptom that had not improved at the time of examination, at least 6 months following surgery. Transient neurological morbidity was defined as any symptom that was recorded following surgery but had completely recovered within 6 months of surgery or by the final examination in the outpatient clinic.

Minor neurological morbidities included Parinaud syndrome and double vision, ability to walk unsupported but with cerebellar symptoms, hypesthesia, and hypacusis. Major neurological morbidities included any paresis of the extremities, cerebellar symptoms with inability to walk unsupported, decrease in vision or consciousness, and mental disorders.

\section{Assessment of Disability and Dependency}

To quantify neurological outcome, with a particular focus on disability and dependency in daily activities, the modified Rankin Scale (mRS) ${ }^{46}$ was used. This tool was initially designed to assess neurological impairment following stroke. Currently, it is also used to evaluate clinical outcome in patients suffering from brain tumors. ${ }^{38}$ The scores range from 0 to 6 , with 0 indicating "no symptoms" and 6 denoting "death."

\section{Evaluation of $\mathrm{HRQOL}$}

HRQOL was evaluated utilizing the European Organisation for Research and Treatment of Cancer (EORTC) quality of life questionnaire-core 30 (QLQ-C30, version 3). ${ }^{1}$ The EORTC QLQ-C30 is a validated ${ }^{42}$ and internationally used questionnaire for assessing the HRQOL of cancer patients. It consists of a global health status/quality of life (QOL) scale, 5 functional scales (physical, role, emotional, cognitive, and social functioning), 3 symptom scales (fatigue, nausea and vomiting, and pain), and 6 single items (dyspnea, insomnia, appetite loss, constipation, diarrhea, and financial difficulties). The single items and scales are each given as percentages of the final score (from $0 \%$ to $100 \%$ ). The global health status and functional scales are scored positively (the higher the score, the better the QOL-respective functioning is). Symptom scales are scored negatively (the higher the score is, the more severe symptoms are).

Each patient completed two EORTC QLQ-C30 questionnaires: one prospectively, as posttest data, concerning the HRQOL at time of completion of the questionnaire, and one retrospectively (pretest data), as a baseline assessment, recalling the time before surgery. To take into account that statistically significant changes in HRQOL scores may not always reflect clinically meaningful changes, ${ }^{35,42}$ changes in HRQOL scores were tested for both statistical signifi- 
cance (using the Wilcoxon test) and clinical significance. Differences in QLQ-C30 mean scores of 0-10 points were classified as not clinically significant, changes of 10-20 points were considered to represent a small clinical effect, and changes of more than 20 points were considered to reflect a large clinical effect. ${ }^{42}$ Measures of HRQOL were compared with normative data on the EORTC QLQ-C30 for the German population.

\section{Subjective Assessment of Tumor-Specific Issues Following Surgery}

All patients furthermore answered 6 dichotomous questions addressing tumor- or surgery-specific issues (e.g., problems with concentration or work ability that they evaluated as being due to their current health status after surgery).

\section{Imaging}

To assess the size and extension of the lesion within the pineal region and to estimate its vicinity to close anatomical structures, such as to the deep veins, contrast-enhanced MR images were obtained in all cases prior to surgery. Furthermore, all patients underwent a postoperative MRI scan to assess the extent of resection. For patients with pineal region tumors, an early postoperative MRI study was performed within 48 hours. For all patients with cysts, follow-up MRI studies were performed within 3 months and served as a basis for comparison of further follow-up imaging.

\section{Statistical Analyses}

Statistical analyses were performed using IBM SPSS version 22.0 (IBM Corp.). To compare 2 related ordinal variables, the Wilcoxon test was used. To analyze 2 unrelated nominal variables, chi-square tests were used; and to quantify the degree of reduction of shunting procedures after removal of the tumor, a 1-sided binominal test was used. ${ }^{33}$ With a given power of $80 \%$, p values $<0.05$ were considered to be significant.

\section{Results \\ Patient Population}

In this study, we prospectively evaluated the postoperative neuropsychological status of 32 patients ( 22 female and 10 male) who had undergone resection of lesions within the pineal region. Of these 32 patients, 20 were suffering from tumors and 12 from cysts. In addition, we retrospectively reviewed the patients' charts, evaluating their characteristics and clinical findings shown in Table 1. The patients' average age at enrollment into the prospective part of the study was 39 years (range 18-73 years). The median duration of follow-up was 40 months (range $7-98$ months). $\mathrm{OH}$ was detected in 20 patients $(63 \%)$ by clinical examination and MRI. Before tumor resection at our department, 6 surgical procedures were performed in 4 patients at other hospitals. In addition, 1 patient was treated with Gamma Knife radiosurgery prior to resective surgery.
TABLE 1. Demographic and clinical characteristics of 32 patients who underwent surgical treatment of pineal region lesions

\begin{tabular}{lc}
\hline \multicolumn{1}{c}{ Characteristic } & Value \\
\hline Age in yrs & 39 \\
\hline Mean & $18-73$ \\
\hline Range & \\
\hline Sex & $22(69)$ \\
\hline Female & $10(31)$ \\
\hline Male & \\
\hline Follow-up in mos & 40 \\
\hline Median & $7-98$ \\
\hline Range & $15(47)$ \\
\hline Preop symptoms & $10(32)$ \\
\hline Cerebellar symptoms & $4(13)$ \\
\hline Parinaud syndrome or double vision & $20(63)$ \\
\hline Visual deficit &
\end{tabular}

Values are number of patients (\%) unless otherwise indicated.

\section{Surgical Approach and Operative Results}

In this current case series, all 32 patients were operated on using an infratentorial supracerebellar approach. In all cases, the operation was performed with the patient in a sitting position. No instance of significant air embolism with $\mathrm{CO}_{2}$ decrease or paradoxical embolism was seen.

As observed on postoperative MRI scans, gross-total resection (GTR) was achieved in $13(65 \%)$ of the 20 tumor cases. Of the 12 patients with cysts, $10(83 \%)$ were treated with radical resection and $2(17 \%)$ with fenestration; both treatments resulted in sufficient drainage of the cyst in all cases. Histopathological results and extent of resections are outlined in Table 2.

\section{Tumor Control}

In addition to pre- and postoperative MRI, in all patients at least 1 further MRI study was performed as a follow-up examination after an average of 32 months. In 15 tumor cases (75\%), GTR was achieved with no tumor recurrence. In 5 cases (25\%), however, remnants or recurrences were seen.

In all 12 patients with pineal cysts, surgery resulted in sufficient drainage of the cyst without any recurrence.

\section{Neurological Outcome}

\section{Mortality and Morbidity}

In this study, we did not observe any mortality or major morbidity associated with the surgery. Minor morbidity, however, occurred in 11 cases; 5 patients had Parinaud syndrome (transient in all 5 cases), 3 patients had double vision (transient in 1 case), 2 patients had cerebellar symptoms (transient in 1 case), and 1 patient had hypacusis. Permanent minor morbidity occurred only in 4 patients $(13 \%)$ (Table 3).

\section{Overall Neurological Status and Long-Term Effects of Surgery} At the time of discharge, $6(30 \%)$ of the 20 patients who 
TABLE 2. Histological diagnosis and surgical treatment

\begin{tabular}{|c|c|c|c|c|c|}
\hline \multirow[b]{2}{*}{ Histology } & \multirow{2}{*}{$\begin{array}{c}\text { No. of Cases } \\
(\%)\end{array}$} & \multicolumn{2}{|c|}{ Tumor Resection } & \multicolumn{2}{|c|}{ Treatment of Cysts } \\
\hline & & GTR & STR & Radical & Fenestration \\
\hline Cyst & $12(38)$ & & & 10 & 2 \\
\hline Pilocytic astrocytoma, WHO grade I & $5(16)$ & 2 & 3 & & \\
\hline Meningioma, WHO grade I & $4(13)$ & 3 & 1 & & \\
\hline Pineal parenchymal tumor, WHO grade II & $4(13)$ & 3 & 1 & & \\
\hline Papillary tumor, WHO grade II & $2(6)$ & 1 & 1 & & \\
\hline Miscellaneous & $5(15)$ & 4 & 1 & & \\
\hline
\end{tabular}

STR = subtotal resection

underwent tumor resection were free of any symptoms, $9(45 \%)$ had experienced improvement, 2 (10\%) had no change from their preoperative status, and only $15 \%(\mathrm{n}=$ 3) demonstrated deterioration of their neurological status. At follow-up, 14 (70\%) of the patients were free of any symptoms; the remaining 6 patients $(30 \%)$ showed improved neurological status during follow-up examinations.

In the group of 12 patients treated for pineal cysts, 1 patient was asymptomatic at discharge and 8 patients $(67 \%)$ showed improvement in their neurological status at discharge; 3 patients $(25 \%)$ showed transient deterioration. With respect to long-term follow-up, however, 5 patients (42\%) were asymptomatic and 7 (58\%) showed improvement over their preoperative and early postoperative neurological status.

\section{Assessment of Disability and Dependency}

The degree of disability in daily activities was assessed using the mRS. We observed statistically significant improvements in $\mathrm{mRS}$ scores following tumor resection (Wilcoxon test, $\mathrm{p}<0.0001$ ) (Fig. 1A). Prior to surgery, $10 \%$ and $35 \%$ of the patients had an mRS score of 0 or 1 , respectively, indicating favorable neurological status, while $15 \%$ had an mRS score of 3 and $10 \%$ had an mRS score of 4 . Following surgery, the proportion of patients with excellent neurological status had significantly improved, with $70 \%$ having an $\mathrm{mRS}$ score of 0 and $25 \%$ having an mRS score of 1 . No patient had an mRS of 5 or 6 at any time point (i.e., in any preoperative, early postoperative, or follow-up examination). Although $15 \%$ and $10 \%$ of patients had mRS scores of 3 or 4 preoperatively, the worst postoperative $\mathrm{mRS}$ score was 2 . Therefore, resection of tumors within the pineal region resulted in an improved neurological status.

In patients with pineal cysts, we observed similar results, with a strong trend of improvement in the mRS score that, however, just failed to demonstrate significance due to the small number of patients. Preoperatively, only $8 \%$ of the patients with pineal cysts had an $\mathrm{mRS}$ score of 0 and $25 \%$ had an mRS score of 1, and after surgery, $25 \%$ and $67 \%$ had an mRS score of 0 or 1 , respectively. Postoperatively, no patient had an $\mathrm{mRS}$ score of 3 or worse, whereas preoperatively $25 \%$ patients had an mRS score of 3 (Fig. 2B).

Our data therefore show that surgical treatment of tumors or cysts within the pineal region results in an improved neurological status and reduced dependency.

\section{Assessment of HRQOL}

Since statistical analysis of changes in HRQOL does not always reflect the clinical significance of these chang$\mathrm{es},{ }^{4}$ the differences in HRQOL were examined for both statistical and clinical significance.

In the group of patients who underwent tumor resection, statistically significant improvements were observed on the global health status/QOL scale and on all functional scales following surgery (Fig. 2A, Table 4).

The greatest improvement was seen in emotional functioning $(Z=-3.668, p<0.0001)$, followed by improvements in the global health status scale $(Z=-3.643, p<$ $0.0001)$, cognitive functioning $(Z=-3.164, p=0.002)$, physical functioning $(\mathrm{Z}=-2.919, \mathrm{p}=0.004)$, role functioning $(Z=-2.788, p=0.005)$, and social functioning $(Z=-2.596, p=0.009)$. On individual symptom scales and items (Fig. 2B), we observed statistically significant improvements in pain $(Z=-3.191, p<0.001)$, nausea and vomiting $(Z=-2.814, p=0.005)$, and fatigue $(Z=-2.694$, $p=0.007)$. There were no statistically significant changes in dyspnea, insomnia, appetite loss, constipation, diarrhea, or financial difficulties.

Assessing the clinical relevance of changes in HRQOL (Fig. 2A, Table 4), improvements, reflected by large clinical effects, were observed for the global health status/ QOL scale; all functional scales; and fatigue, nausea and vomiting, and pain. A small clinical effect was observed for insomnia.

We also observed significant improvements on the global health status/QOL scale and on all functional scales after resection of pineal cysts (Fig. 3A, Table 5). Arranged according to $\mathrm{p}$ values, the greatest improvement occurred on the global health status/QOL scale $(Z=-2.760, p=0.006)$, followed by role functioning $(Z=-2.871, p=0.004)$, physical functioning $(\mathrm{Z}=-2.552, \mathrm{p}=0.011)$, cognitive function-

\section{TABLE 3. Postoperative morbidity}

\begin{tabular}{lcc}
\hline \multicolumn{1}{c}{ Morbidity* } & Temporary Deficits & Permanent Deficits \\
\hline Parinaud syndrome & 5 & 0 \\
\hline Double vision & 1 & 2 \\
\hline Cerebellar symptoms & 1 & 1 \\
\hline Hypacusis & 0 & 1 \\
\hline
\end{tabular}

* All instances of morbidity were considered minor. No patient died or suffered any major morbidity. 

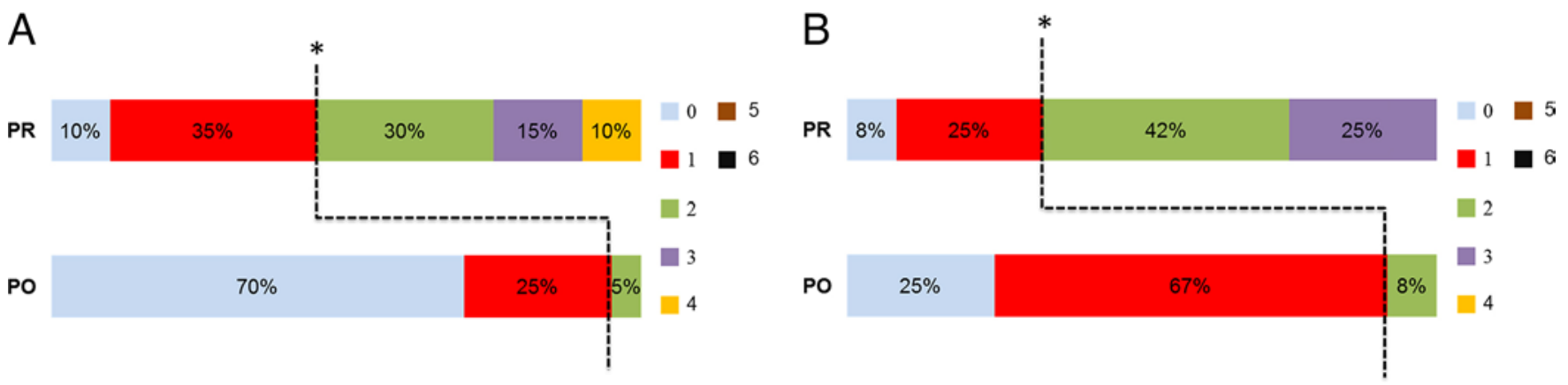

FIG. 1. Disability and dependency assessed by $\mathrm{mRS}$ in 20 patients who underwent resection of pineal region tumors $(\mathbf{A})$ and 12 patients who underwent surgical treatment of pineal cysts (B). The bar graphs present preoperative (PR) and postoperative (PO) $\mathrm{mRS}$ scores (indicated by color). The percentage values indicate the proportion of patients with the specified score. Figure is available in color online only.

ing $(\mathrm{Z}=-2.373, \mathrm{p}=0.018)$, emotional functioning $(\mathrm{Z}=$ $-2.458, \mathrm{p}=0.14)$, and social functioning $(\mathrm{Z}=-2.448, \mathrm{p}=$ $0.014)$, respectively.

On single-symptom scales and items (Fig. 3B), statistical improvements were reached in fatigue $(\mathrm{Z}=-2.419, \mathrm{p}=$ $0.016)$, nausea and vomiting $(\mathrm{Z}=-2.388, \mathrm{p}=0.017)$, and pain $(Z=-2.257, p=0.024)$. Assessing clinical relevance of the changes in HRQOL after the surgical treatment of cysts (Table 5), we noticed improvements in terms of a large clinical effect for global health status/QOL scale, physical functioning, role functioning, emotional functioning, social functioning, fatigue, nausea and vomiting, pain, and insomnia. A small clinical effect was additionally observed for cognitive functioning.

\section{Subjective Assessment of Health Status}

All patients answered surgery-specific questions evalu- ating their subjective assessment of health status and satisfaction with the surgery. In the tumor resection group, $70 \%$ of patients indicated that they felt considerably better, $20 \%$ indicated that they felt a bit better, and $10 \%$ indicated that they could not detect any difference. Of patients treated for pineal cysts, 33\% indicated that they felt significantly better, $42 \%$ indicated that they felt a bit better, and $25 \%$ indicated that they could not observe any change. No patient evaluated his or her postoperative status as worse than prior to surgery. Overall, $91 \%$ indicated that they would make the same choice to undergo surgery again.

\section{Temporary and Permanent CSF Diversion}

$\mathrm{OH}$ was diagnosed preoperatively in $14(70 \%)$ of the patients with tumors and in $6(50 \%)$ of the patients with pineal cysts. One patient had already undergone a shunt placement procedure before treatment at our department.

A
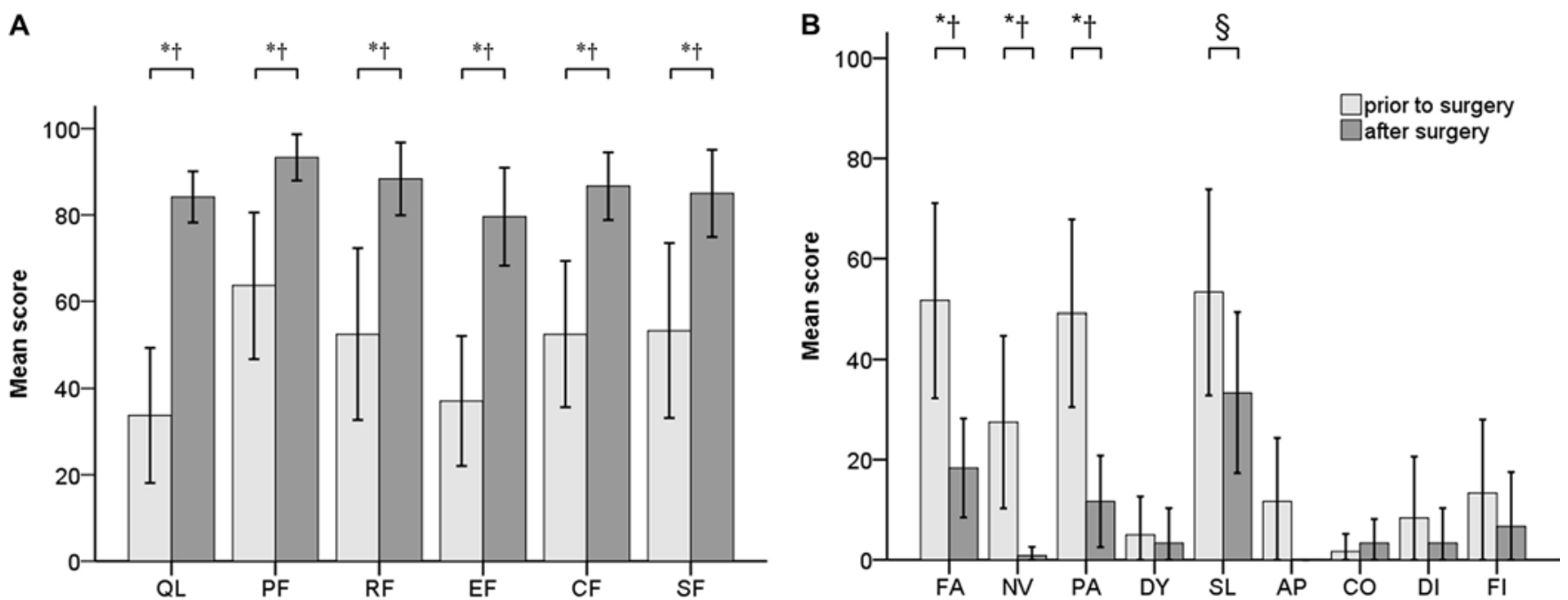

FIG. 2. Comparison of pre- and postoperative HRQOL in patients who underwent resection of pineal region tumors. Values are given as means with $95 \%$ confidence intervals. A: Statistical and clinical assessment of global health status and functional scales. B: Symptom scales and single items. AP = appetite loss; $C F=$ cognitive functioning; $C O=$ constipation; $D I=$ diarrhea; $D Y$ = dyspnea; $\mathrm{EF}=$ emotional functioning; $\mathrm{FA}=$ fatigue; $\mathrm{FI}=$ financial difficulties; $\mathrm{NV}=$ nausea and vomiting; $\mathrm{PA}=$ pain; $\mathrm{PF}=$ physical functioning; $\mathrm{QL}=$ global health status; $\mathrm{RF}=$ role functioning; $\mathrm{SL}=$ insomnia; $\mathrm{SF}=$ social functioning. ${ }^{*} \mathrm{p}<0.05$ (statistically significant); $†=$ large clinical effect; $\S=$ small clinical effect; both effects are given as difference in QLQ-C30 mean scores. 
TABLE 4. Effect of surgery on HRQOL scores

\begin{tabular}{|c|c|c|c|c|c|c|}
\hline \multirow[b]{2}{*}{ Variable } & \multicolumn{2}{|c|}{ Mean (SD) HRQOL Score } & \multicolumn{2}{|l|}{ Clin Significance } & \multicolumn{2}{|c|}{ Stat Significance } \\
\hline & Preop & Postop & Diff in Mean Score $(95 \% \mathrm{Cl})$ & Effect & Z & p Value \\
\hline Global health status & 33.75 (33.39) & $84.16(12.65)$ & $50.41(34.14-66.69)$ & $\dagger$ & -3.643 & $<0.0001$ \\
\hline Physical functioning & $63.67(36.09)$ & $93.33(11.44)$ & $29.66(11.60-47.73)$ & $\dagger$ & -2.919 & 0.004 \\
\hline Role functioning & $52.50(42.33)$ & $88.33(18.02)$ & $35.83(13.02-58.65)$ & $\dagger$ & -2.788 & 0.005 \\
\hline Emotional functioning & $37.08(32.16)$ & $79.58(24.25)$ & $42.50(27.64-57.36)$ & $\dagger$ & -3.668 & $<0.0001$ \\
\hline Cognitive functioning & $52.50(35.98)$ & $86.67(16.75)$ & $34.17(16.91-51.42)$ & $\dagger$ & -3.164 & 0.002 \\
\hline Social functioning & $53.33(43.12)$ & $85.00(21.56)$ & $31.67(10.97-52.37)$ & $\dagger$ & -2.596 & 0.009 \\
\hline Fatigue & $51.67(41.46)$ & $18.33(21.10)$ & $-33.34(-54.61$ to -12.06$)$ & $\dagger$ & -2.694 & 0.007 \\
\hline Nausea \& vomiting & $27.50(36.78)$ & $0.83(3.73)$ & $-26.67(-43.15$ to -10.19$)$ & $\dagger$ & -2.814 & 0.005 \\
\hline Pain & $49.17(39.91)$ & $11.67(19.57)$ & $-37.50(-54.83$ to -20.17$)$ & $\dagger$ & -3.191 & 0.001 \\
\hline Dyspnea & $5.00(16.31)$ & $3.33(14.91)$ & $-1.67(-12.37$ to 9.04$)$ & NCS & -0.272 & NS \\
\hline Insomnia & $53.33(43.80)$ & $33.33(34.20)$ & $-20.00(-49.25$ to 9.25$)$ & $\S$ & -1.305 & NS \\
\hline Appetite loss & $11.67(27.01)$ & $0.00(0.00)$ & $-11.67(-24.35$ to 1.01$)$ & NCS & -1.841 & NS \\
\hline Constipation & $1.67(7.45)$ & $3.33(10.26)$ & $1.63(-1.82$ to 5.16$)$ & NCS & -1.00 & NS \\
\hline Diarrhea & $8.33(26.21)$ & $3.33(14.91)$ & $-5.00(-12.63$ to 2.63$)$ & NCS & -1.342 & NS \\
\hline Financial difficulties & $13.33(31.34)$ & $6.67(23.20)$ & $-6.66(-23.91$ to 10.57$)$ & NCS & -0.816 & NS \\
\hline
\end{tabular}

Clin = clinical; diff = difference; NCS = not clinically significant; NS = not statistically significant; stat = statistical.

$\dagger$ Large clinical significance.

$\S$ Small clinical significance.

Because of persistent hydrocephalus, permanent CSF diversion (ventriculoperitoneal shunt placement) was performed in 4 patients after tumor resection and in 1 patient following surgery on pineal cysts.

Of the 13 patients suffering from $\mathrm{OH}$ preoperatively and not having undergone shunt placement before surgical treatment of their cyst or tumor, permanent CSF diversion was only required in 4 cases. Assuming the necessity for permanent CSF diversion in $\geq 45 \%$ of the patients with
$\mathrm{OH}$ caused by lesions within the pineal region, surgical treatment of the lesion thus significantly reduced the need for permanent CSF shunting (1-sided binominal test, $\mathrm{p}<$ 0.05 ).

Assessing the effect of the extent of resection on permanent shunt diversion in this group of patients, we observed a significantly reduced need for shunting procedures (chi-square test, $\mathrm{p}=0.024$ ) after GTR when compared with STR.
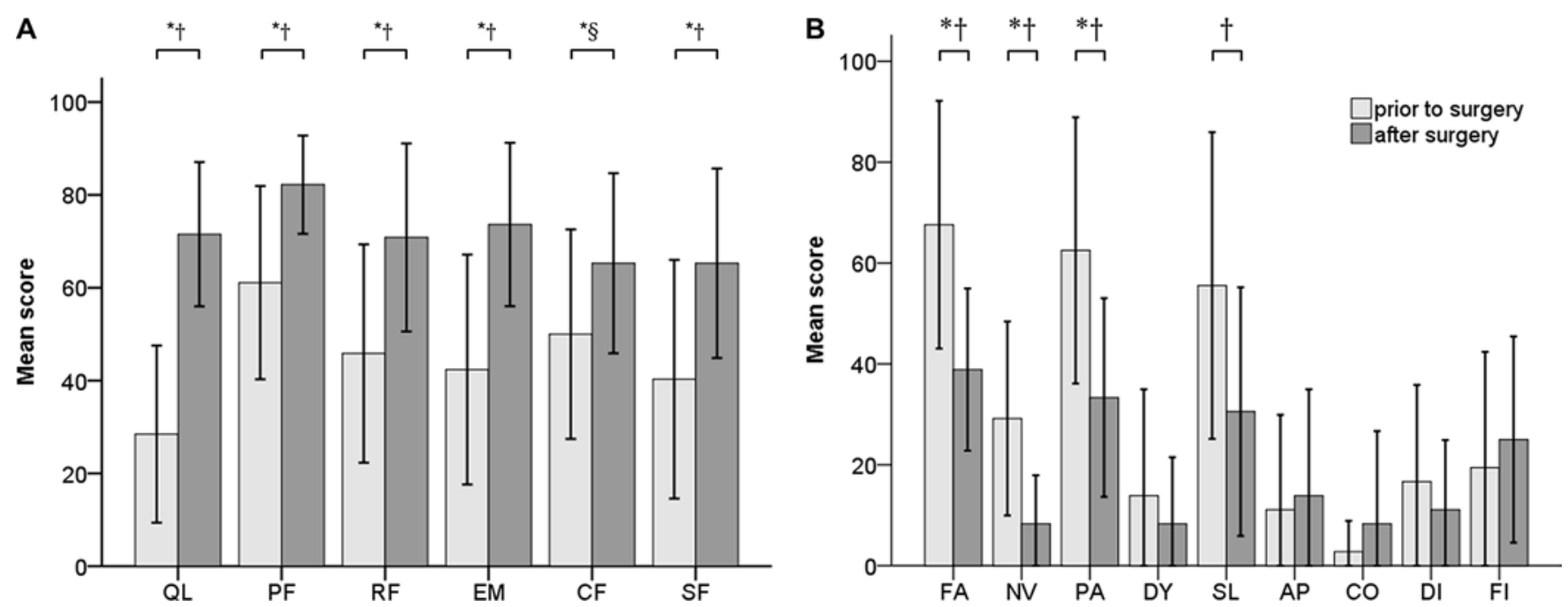

FIG. 3. Comparison of pre- and postoperative HRQOL in patients who underwent surgical treatment of pineal cysts. Values are given as means with $95 \%$ confidence intervals. A: Statistical and clinical assessment of global health status and functional scales. B: Symptom scales and single items. AP = appetite loss; $\mathrm{CF}=$ cognitive functioning; $\mathrm{CO}=$ constipation; $\mathrm{DI}=$ diarrhea; $\mathrm{DY}=$ dyspnea; $\mathrm{EF}=$ emotional functioning; $\mathrm{FA}=$ fatigue; $\mathrm{FI}$ = financial difficulties; $\mathrm{NV}=$ nausea and vomiting; $\mathrm{PA}=$ pain; $\mathrm{PF}$ = physical functioning; $\mathrm{QL}=$ global health status; $\mathrm{RF}=$ role functioning; $\mathrm{SL}=$ insomnia; $\mathrm{SF}=$ social functioning. ${ }^{*} p<0.05$ (statistically significant); $\dagger=$ large clinical effect; $\S=$ small clinical effect; both effects are given as difference in QLQ-C30 mean scores. 


\section{Discussion}

Today, the aim of surgery on lesions within the pineal region is not only to obtain a histological diagnosis to facilitate the planning of further treatment, ${ }^{4}$ but also to remove the lesion. In recent years, radical resection without loss of neurological function has been considered to be the principal aim of surgical therapy for most pineal region tumors, $7,21,30,45$ with the exception of germinomas and nongerminomatous malignant germ cell tumors. ${ }^{26,36,49,58,59}$ It has been shown that radical resection of benign tumors/ lesions can be curative., ${ }^{9,12,34}$ In the case of malignant tumors, although radical resection may not cure the condition, it can result in significantly longer survival rates than are seen in patients who undergo only biopsy or partial resection. ${ }^{30}$ Another important advantage of radical tumor removal lies in the reopening of the blocked aqueduct, thus reestablishing CSF circulation and eliminating the need for further CSF shunt procedures. However, data confirming this advantage are not available yet.

In this study, we were able to show that surgical treatment of lesions of the pineal region leads to an improvement of the neurological status and HRQOL, in terms of both statistical significance and clinical relevance. Furthermore, we were able to demonstrate for the first time that radical resection (GTR) of the lesion reduces the necessity for further CSF shunting procedures.

\section{Mortality and Morbidity}

In this case series, there was no major morbidity. Permanent minor morbidity occurred in 4 patients (13\%). Fur- thermore, there was no mortality related to the surgical procedure. These results are in concordance with the recent literature (Table 5). ${ }^{7-10,12,18,21,22,24,29,30,36,40,43,47,51,57}$ Transient neurological deficits, characterized by spontaneous recovery within a couple of months, however, occurred more frequently, both in the literature $(9 \%-57 \%)$ and in our own study $(22 \%) .8,10,21,23,40$

In a large case series including 160 patients with pineal lesion tumors, Bruce and Stein ${ }^{8}$ observed an excellent outcome for more than $90 \%$ of the patients; the mortality rate in that series was $4 \%$ and the rate of permanent major morbidity was $3 \%$. Pendl ${ }^{43}$ showed that neurological status improved postoperatively in $71 \%$ of patients, remained unchanged in $22 \%$, and worsened in only $7 \%$. Similarly, Konovalov and Pitskhelauri ${ }^{30}$ reported improvement in $77 \%$ of patients who survived the immediate postoperative period, no change in 13\%, and permanent major morbidity in $10 \%$. Kodera et al. ${ }^{29}$ were even able to report improvement in $96 \%$ of their small series of 26 patients, with no change from preoperative condition in the remaining $4 \%$. Our results are in accordance with these findings. The majority of patients who were assessed on the long-term effects of the surgical treatment of tumors or cysts in our study were free of symptoms (70\% of those in the tumor group and $42 \%$ of those in the cyst group) or experienced improvement (30\% and $58 \%$, respectively).

Based on analysis of the current literature and our own results, resection of lesions within the pineal region appears safe and is associated with only a low rate of severe morbidity or mortality.

TABLE 5. Surgical treatment of lesions within the pineal region: summary of case series published since 1980

\begin{tabular}{|c|c|c|c|c|c|c|c|c|}
\hline Authors \& Year & $\begin{array}{l}\text { Described } \\
\text { Time Interval }\end{array}$ & $\begin{array}{l}\text { No. of } \\
\text { Pts }\end{array}$ & $\begin{array}{l}\text { No. of } \\
\text { Ops }\end{array}$ & Mortality & $\begin{array}{c}\text { Major } \\
\text { Morbidity }\end{array}$ & $\begin{array}{c}\text { Minor } \\
\text { Morbidity }\end{array}$ & Surgical Approach & $\begin{array}{c}\text { GTR } \\
\%\end{array}$ \\
\hline Vaquero et al., 1992 & 1972-1992 & 29 & 29 & $3(10 \%)$ & NR & NR & SCI, OT, ITC & NR \\
\hline Herrmann et al., 1992 & 1980-1992 & 49 & 49 & $4(8 \%)$ & NR & NR & $\mathrm{SCl}, \mathrm{OT}$ & NR \\
\hline Bruce \& Stein, 1995 & NR & 154 & 160 & $6(4 \%)$ & $4(3 \%)$ & $32(21 \%)$ & SCI, OT, ITC & $45 \%$ \\
\hline Matsutani et al., 1997 & 1980-1994 & 45 & 45 & $2(4 \%)$ & $2(4 \%)$ & NR & $\mathrm{SCl}, \mathrm{OT}$ & NR \\
\hline Fukui et al., 1998 & $1976-1997$ & 20 & 20 & $2(10 \%)$ & $2(10 \%)$ & $1(5 \%)$ & $\mathrm{SCl}, \mathrm{OT}$ & $65 \%$ \\
\hline Chandy \& Damaraju, 1998 & 1983-1997 & 43 & 44 & $0(0 \%)$ & NR & NR & $\mathrm{SCl}, \mathrm{OT}$ & $55 \%$ \\
\hline Cho et al., 1998 & $1986-1995$ & 33 & 33 & $0(0 \%)$ & $6(18 \%)$ & $7(21 \%)$ & OT & $55 \%$ \\
\hline Kang et al., 1998 & $1986-1996$ & 16 & 16 & $0(0 \%)$ & $3(19 \%)$ & $0(0 \%)$ & SCI, OT, ITC & $38 \%$ \\
\hline Shin et al., 1998 & 1989-1995 & 21 & 21 & $0(0 \%)$ & $1(5 \%)$ & $5(24 \%)$ & OT & $43 \%$ \\
\hline Pendl, 2002 & $1975-2002$ & 110 & 112 & $3(3 \%)$ & $4(4 \%)$ & NR & SCI, OT, ITC, subtemp, transventr & $69 \%$ \\
\hline \multirow[t]{2}{*}{ Konovalov \& Pitskhelauri, 2003} & $1976-1999$ & 244 & 255 & $20(8 \%)$ & NR & NR & SCI, OT, subchor, through 4th ventricle & $58 \%$ \\
\hline & 1990-1999 & 168 & NR & $3(2 \%)$ & NR & NR & $\mathrm{SCl}, \mathrm{OT}$ & NR \\
\hline Desai et al., 2006 & 1992-2003 & 24 & 25 & $0(0 \%)$ & $0(0 \%)$ & $0(0 \%)$ & SCI, ITC & $18 \%$ \\
\hline Bruce \& Ogden, 2004 & NR & 81 & NR & $1(1 \%)$ & $2(2 \%)$ & NR & SCI, OT, ITC & $47 \%$ \\
\hline Hernesniemi et al., 2008 & 1980-2007 & 119 & 119 & $0(0 \%)$ & $2(2 \%)$ & $2(2 \%)$ & SCI, ITC & $88 \%$ \\
\hline Sajko et al., 2009 & 1990-2007 & 39 & 39 & $0(0 \%)$ & $2(5 \%)$ & $4(10 \%)$ & $\mathrm{SCl}$ & $59 \%$ \\
\hline Kodera et al., 2011 & 1997-2006 & 26 & 26 & $0(0 \%)$ & $0(0 \%)$ & $0(0 \%)$ & $\mathrm{SCl}$ & $88 \%$ \\
\hline Jia et al., 2011 & $1997-2007$ & 150 & 150 & $0(0 \%)$ & $0(0 \%)$ & NR & ITC & $86 \%$ \\
\hline Oliveira et al., 2013 & 1993-2012 & 32 & 32 & $0(0 \%)$ & $0(0 \%)$ & $0(0 \%)$ & $\mathrm{SCl}$ & $50 \%$ \\
\hline
\end{tabular}

ITC = interhemispheric transcallosal; NR = not reported; OT = occipital transtentorial; pt = patient; $\mathrm{SCl}$ = supracerebellar infratentorial; subchor = subchoroidal; subtemp = subtemporal; transventr $=$ transventricular. 


\section{HRQOL and Self-Assessment After Surgery}

To the best of our knowledge, this is the first study to systematically assess HRQOL after the surgical treatment of lesions of the pineal region. Especially in patients with rare tumor entities, HRQOL has been neglected for a long time..$^{15}$

In this study, we were able to demonstrate that the surgical removal of pineal region tumors improves HRQOL. The greatest improvements occurred on the emotional functioning scale, followed by the global health status/ QOL scale. Preoperatively, the majority of patients reported feeling emotional distress and uncertainty because of the presence of a tumor in this specific location. In light of this, the significant improvement in emotional functioning is likely due to the fact that patients were released from the burden of the tumor after surgery. The improvement in emotional functioning may also be a result of a good surgical outcome in terms of neurological symptoms and local tumor control that could be achieved in $100 \%$ of patients. This is a very important aspect of surgery for pineal region tumors; as emotional distress influences attention, vigilance, and motivation, ${ }^{54}$ local tumor control might thus affect several cognitive domains.

Despite the fact that some patients were still suffering from symptoms following surgery and a few of them even had new neurological deficits, the overall majority was satisfied with the surgery and would undergo the same procedure again $(91 \%)$. Another notable fact is that $94 \%$ of the patients had already returned to work at the time of follow-up.

Considering these results, and in light of the low mortality and morbidity rate, surgical removal appears not only acceptable, but also advisable for patients with lesions of the pineal region.

\section{Surgical Approach}

The most frequently used techniques to reach the pineal region are the supracerebellar infratentorial, interhemispheric transcallosal, and occipital transtentorial approaches. In our series, all operations were performed using the supracerebellar infratentorial approach with the patient in a sitting position. Tumor resection using this approach offers many advantages, such as spontaneous sinking of the cerebellum, which creates a corridor between the cerebellum and the tentorium; spontaneous drainage of blood and CSF out of the surgical field; and decrease of cerebral venous pressure. Nevertheless, because of well-known possible complications, including arterial emboli, paradoxical air embolism, and pneumocephalus, the use of this approach has critically been discussed. ${ }^{16,31,48}$

In a systematic review including 4806 cases, Fathi et al. demonstrated that venous air embolism could be detected by means of echocardiography in 39\% of patients during posterior fossa surgery, while paradoxical air embolism became evident in only $0 \%-14 \% .{ }^{17}$ To avoid this risk, patent foramen ovale (PFO) closure is recommended; most common closure devices achieve $99 \%$ success rates with a $<1 \%$ minor risk of embolism. ${ }^{17}$

Furthermore, in studies by Di Lorenzo et al..$^{13}$ and Kishan et al., ${ }^{28}$ the finding of pneumocephalus on postoperative images is described in $100 \%$ of patients following surgery in the sitting position. However, tension pneumocephalus occurred in only 2 of 90 cases. In addition, other complications, such as supratentorial intracerebral hemorrhage ${ }^{50}$ or cervical myelopathy, ${ }^{20}$ have also been described.

In our series, we encountered no clinically relevant venous air embolism, paradoxical air embolism, or pneumocephalus or any other position-related complication causing deterioration in neurological status or requiring further surgery. These results are in concordance with most current studies, in which the sitting position is described as safe and most favorable for approaches to the pineal region. ${ }^{6,21,25,32}$

\section{Treatment Strategies for $\mathrm{OH}$}

Obstructive hydrocephalus is a threatening complication associated with lesions within the pineal region blocking the aqueduct. In current literature, the reported incidence varies according to the entity of the lesion and ranges between $55 \%$ and $90 \% .^{10,29,30,47,52}$ Therefore, many patients need further treatment in the form of CSF shunt procedures or endoscopic third ventriculostomy.

In our study, $\mathrm{OH}$ occurred in $63 \%$ of cases. Comparing gross-total and subtotal tumor resections, we were able to demonstrate for the first time that radical tumor removal reduces the necessity of CSF shunt operations. These results further confirm our hypothesis that GTR of lesions within the pineal region is more beneficial than partial resection or biopsy.

\section{Limitations}

The study does have some limitations. The main limitations are the limited number of patients and the partly retrospective design. These are common issues in the evaluation of the surgical treatment of pineal region tumors, in particular since lesions in this area are rare and show a high histological diversity. As an illustration of the rarity of these tumors, the mean number of patients in available studies is $63 \pm 6$ and the mean duration of the study period is $17 \pm 6$ years. ${ }^{3,9,10,12,14,18,21,22,24,27,29,30,36,37,40,43,47,51,57}$

\section{Conclusions}

In summary, we were able to demonstrate in this study that surgical treatment of lesions within the pineal region not only improves neurological status and decreases disability in most cases but also significantly increases the patients' HRQOL. Furthermore, radical tumor resection or cyst removal decreases the need for shunt procedures. With the exception of a few diagnoses, radical resection of lesions of the pineal region thus should be considered as the primary treatment modality in most cases.

\section{References}

1. Aaronson NK, Ahmedzai S, Bergman B, Bullinger M, Cull A, Duez NJ, et al: The European Organization for Research and Treatment of Cancer QLQ-C30: a quality-of-life instrument for use in international clinical trials in oncology. $\mathbf{J}$ Natl Cancer Inst 85:365-376, 1993

2. Arpinelli F, Bamfi F: The FDA guidance for industry on PROs: the point of view of a pharmaceutical company. Health Qual Life Outcomes 4:85, 2006 
3. Bitzer EM, Petrucci M, Lorenz C, Hussein R, Dörning H, Trojan A, et al: A comparison of conventional and retrospective measures of change in symptoms after elective surgery. Health Qual Life Outcomes 9:23, 2011

4. Blakeley JO, Grossman SA: Management of pineal region tumors. Curr Treat Options Oncol 7:505-516, 2006

5. Bruce J: Management of pineal region tumors. Neurosurg $\mathbf{Q}$ 3:103-119, 1993

6. Bruce JN: Sitting position for the removal of pineal region lesions. World Neurosurg 77:657-658, 2012

7. Bruce JN, Ogden AT: Surgical strategies for treating patients with pineal region tumors. J Neurooncol 69:221-236, 2004

8. Bruce JN, Stein BM: Surgical management of pineal region tumors. Acta Neurochir (Wien) 134:130-135, 1995

9. Chandy MJ, Damaraju SC: Benign tumours of the pineal region: a prospective study from 1983 to 1997 . Br J Neurosurg 12:228-233, 1998

10. Cho BK, Wang KC, Nam DH, Kim DG, Jung HW, Kim HJ, et al: Pineal tumors: experience with 48 cases over 10 years. Childs Nerv Syst 14:53-58, 1998

11. Choudhry O, Gupta G, Prestigiacomo CJ: On the surgery of the seat of the soul: the pineal gland and the history of its surgical approaches. Neurosurg Clin N Am 22:321-333, vii, 2011

12. Desai KI, Nadkarni TD, Fattepurkar SC, Goel AH: Pineal epidermoid cysts: a study of 24 cases. Surg Neurol 65:124129, 2006

13. Di Lorenzo N, Caruso R, Floris R, Guerrisi V, Bozzao L, Fortuna A: Pneumocephalus and tension pneumocephalus after posterior fossa surgery in the sitting position: a prospective study. Acta Neurochir (Wien) 83:112-115, 1986

14. Dirven L, Reijneveld JC, Aaronson NK, Bottomley A, Uitdehaag BMJ, Taphoorn MJB: Health-related quality of life in patients with brain tumors: limitations and additional outcome measures. Curr Neurol Neurosci Rep 13:359, 2013

15. Efficace F, Bottomley A: Health related quality of life assessment methodology and reported outcomes in randomised controlled trials of primary brain cancer patients. Eur $\mathbf{J}$ Cancer 38:1824-1831, 2002

16. Engelhardt M, Folkers W, Brenke C, Scholz M, Harders A, Fidorra H, et al: Neurosurgical operations with the patient in sitting position: analysis of risk factors using transcranial Doppler sonography. Br J Anaesth 96:467-472, 2006

17. Fathi AR, Eshtehardi P, Meier B: Patent foramen ovale and neurosurgery in sitting position: a systematic review. Br J Anaesth 102:588-596, 2009

18. Fukui M, Natori Y, Matsushima T, Nishio S, Ikezaki K: Operative approaches to the pineal region tumors. Childs Nerv Syst 14:49-52, 1998

19. Graziano SL, Paolozzi FP, Rudolph AR, Stewart WA, Elbadawi A, Comis RL: Mixed germ-cell tumor of the pineal region. Case report. J Neurosurg 66:300-304, 1987

20. Haisa T, Kondo T: Midcervical flexion myelopathy after posterior fossa surgery in the sitting position: case report. Neurosurgery 38:819-822, 1996

21. Hernesniemi J, Romani R, Albayrak BS, Lehto H, Dashti R, Ramsey C III, et al: Microsurgical management of pineal region lesions: personal experience with 119 patients. Surg Neurol 70:576-583, 2008

22. Herrmann HD, Winkler D, Westphal M: Treatment of tumours of the pineal region and posterior part of the third ventricle. Acta Neurochir (Wien) 116:137-146, 1992

23. Jia W, Ma Z, Liu IY, Zhang Y, Jia G, Wan W: Transcallosal interforniceal approach to pineal region tumors in 150 children. J Neurosurg Pediatr 7:98-103, 2011

24. Kang JK, Jeun SS, Hong YK, Park CK, Son BC, Lee IW, et al: Experience with pineal region tumors. Childs Nerv Syst 14:63-68, 1998

25. Kanno T, Kiya N, Akashi K, Harada S: Infratentorial supra- cerebellar approach for pineal lesions. Oper Tech Neurosurg 6:222-230, 2003

26. Kersh CR, Constable WC, Eisert DR, Spaulding CA, Hahn SS, Jenrette JM III, et al: Primary central nervous system germ cell tumors. Effect of histologic confirmation on radiotherapy. Cancer 61:2148-2152, 1988

27. Kiebert GM, van Oosterhout EC, van Bronswijk H, Lemkes HH, Gooszen HG: Quality of life after combined kidneypancreas or kidney transplantation in diabetic patients with end-stage renal disease. Clin Transplant 8:239-245, 1994

28. Kishan A, Naidu MR, Muralidhar K: Tension pneumocephalus following posterior fossa surgery in sitting position. A report of 2 cases. Clin Neurol Neurosurg 92:245-248, 1990

29. Kodera T, Bozinov O, Sürücü O, Ulrich NH, Burkhardt JK, Bertalanffy H: Neurosurgical venous considerations for tumors of the pineal region resected using the infratentorial supracerebellar approach. J Clin Neurosci 18:1481-1485, 2011

30. Konovalov AN, Pitskhelauri DI: Principles of treatment of the pineal region tumors. Surg Neurol 59:250-268, 2003

31. Leonard IE, Cunningham AJ: The sitting position in neurosurgery-not yet obsolete! Br J Anaesth 88:1-3, 2002

32. Lindroos AC, Niiya T, Randell T, Romani R, Hernesniemi J, Niemi T: Sitting position for removal of pineal region lesions: the Helsinki experience. World Neurosurg 74:505-513, 2010

33. Lydersen S, Fagerland MW, Laake P: Recommended tests for association in 2 × 2 tables. Stat Med 28:1159-1175, 2009

34. Macchi MM, Bruce JN: Human pineal physiology and functional significance of melatonin. Front Neuroendocrinol 25:177-195, 2004

35. Maringwa J, Quinten C, King M, Ringash J, Osoba D, Coens $\mathrm{C}$, et al: Minimal clinically meaningful differences for the EORTC QLQ-C30 and EORTC QLQ-BN20 scales in brain cancer patients. Ann Oncol 22:2107-2112, 2011

36. Matsutani M, Sano K, Takakura K, Fujimaki T, Nakamura O, Funata N, et al: Primary intracranial germ cell tumors: a clinical analysis of 153 histologically verified cases. J Neurosurg 86:446-455, 1997

37. McPhail S, Haines T: Response shift, recall bias and their effect on measuring change in health-related quality of life amongst older hospital patients. Health Qual Life Outcomes 8:65, 2010

38. Meyer FB, Bates LM, Goerss SJ, Friedman JA, Windschitl WL, Duffy JR, et al: Awake craniotomy for aggressive resection of primary gliomas located in eloquent brain. Mayo Clin Proc 76:677-687, 2001

39. Mottolese C, Szathmari A, Beuriat PA: Incidence of pineal tumours. A review of the literature. Neurochirurgie 61:6569,2015

40. Oliveira J, Cerejo A, Silva PS, Polónia P, Pereira J, Vaz R: The infratentorial supracerebellar approach in surgery of lesions of the pineal region. Surg Neurol Int 4:154, 2013

41. Osoba D, Aaronson NK, Muller M, Sneeuw K, Hsu MA, Yung WK, et al: Effect of neurological dysfunction on health-related quality of life in patients with high-grade glioma. J Neurooncol 34:263-278, 1997

42. Osoba D, Rodrigues G, Myles J, Zee B, Pater J: Interpreting the significance of changes in health-related quality-of-life scores. J Clin Oncol 16:139-144, 1998

43. Pendl G: Management of pineal region tumors. Neurosurg $\mathbf{Q}$ 12:279-298, 2002

44. Poppen JL, Marino R Jr: Pinealomas and tumors of the posterior portion of the third ventricle. J Neurosurg 28:357364, 1968

45. Radovanovic I, Dizdarevic K, de Tribolet N, Masic T, Muminagic S: Pineal region tumors-neurosurgical review. Med Arh 63:171-173, 2009

46. Rankin J: Cerebral vascular accidents in patients over the age of 60. II. Prognosis. Scott Med J 2:200-215, 1957 
47. Sajko T, Kudelić N, Lupret V, Lupret V Jr, Nola IA: Treatment of pineal region lesions: our experience in 39 patients. Coll Antropol 33:1259-1263, 2009

48. Schaffranietz L, Grothe A, Olthoff D: [Use of the sitting position in neurosurgery. Results of a 1998 survey in Germany.] Anaesthesist 49:269-274, 2000 (Ger)

49. Schild SE, Scheithauer BW, Haddock MG, Wong WW, Lyons MK, Marks LB, et al: Histologically confirmed pineal tumors and other germ cell tumors of the brain. Cancer 78:25642571, 1996

50. Seiler RW, Zurbrügg HR: Supratentorial intracerebral hemorrhage after posterior fossa operation. Neurosurgery 18:472-474, 1986

51. Shin HJ, Cho BK, Jung HW, Wang KC: Pediatric pineal tumors: need for a direct surgical approach and complications of the occipital transtentorial approach. Childs Nerv Syst 14:174-178, 1998

52. Stein BM, Bruce JN: Surgical management of pineal region tumors (honored guest lecture). Clin Neurosurg 39:509-532, 1992

53. Taphoorn MJB, Claassens L, Aaronson NK, Coens C, Mauer M, Osoba D, et al: An international validation study of the EORTC brain cancer module (EORTC QLQ-BN20) for assessing health-related quality of life and symptoms in brain cancer patients. Eur J Cancer 46:1033-1040, 2010

54. Taphoorn MJB, Klein M: Cognitive deficits in adult patients with brain tumours. Lancet Neurol 3:159-168, 2004

55. Taphoorn MJB, Stupp R, Coens C, Osoba D, Kortmann R, van den Bent MJ, et al: Health-related quality of life in patients with glioblastoma: a randomised controlled trial. Lancet Oncol 6:937-944, 2005

56. Tirakotai W, Riegel T, Stiegel A, Hellwig D, Heinze S, Bertalanffy $\mathrm{H}$, et al: Peri-operative quality of life assessment in endoscopically treated patients with pineal region tumours. Childs Nerv Syst 23:659-663, 2007
57. Vaquero J, Ramiro J, Martínez R, Bravo G: Neurosurgical experience with tumours of the pineal region at Clinica Puerta de Hierro. Acta Neurochir (Wien) 116:23-32, 1992

58. Weiner HL, Lichtenbaum RA, Wisoff JH, Snow RB, Souweidane MM, Bruce JN, et al: Delayed surgical resection of central nervous system germ cell tumors. Neurosurgery 50:727-734, 2002

59. Wolden SL, Wara WM, Larson DA, Prados MD, Edwards MS, Sneed PK: Radiation therapy for primary intracranial germ-cell tumors. Int J Radiat Oncol Biol Phys 32:943949, 1995

\section{Disclosures}

The authors report no conflict of interest concerning the materials or methods used in this study or the findings specified in this paper.

\section{Author Contributions}

Conception and design: all authors. Acquisition of data: Fedorko. Analysis and interpretation of data: Fedorko. Drafting the article: Zweckberger, Fedorko. Critically revising the article: all authors. Reviewed submitted version of manuscript: Zweckberger, Unterberg. Approved the final version of the manuscript on behalf of all authors: Zweckberger. Statistical analysis: Fedorko. Administrative/technical/material support: Unterberg. Study supervision: Zweckberger, Unterberg.

\section{Correspondence}

Klaus Zweckberger: University of Heidelberg, Germany. klaus. zweckberger@med.uni-heidelberg.de. 